\title{
Educação ambiental na escola: 0 trabalho desenvolvido por professores de um colégio do interior do Paraná
}

\author{
Environmental education at school: a project developed \\ in the state of Paraná
}

\author{
Rosângela Batista Lins* \\ Lisandra Almeida Lisovski
}

\begin{abstract}
Resumo: No presente artigo buscou-se analisar como os professores de uma escola pública do interior do Estado do Paraná trabalham a Educação Ambiental em suas disciplinas e a importância que atribuem à mesma. Trata-se de uma pesquisa de cunho qualitativo que envolveu oito professores de diferentes áreas do conhecimento que atuam no Ensino Fundamental. Os dados foram coletados por meio da aplicação de questionários; após a sua tabulação, foi possível verificar que os temas relacionados com o meio ambiente são trabalhados por alguns professores, mas de forma pontual, sem relação entre os mesmos, e que os professores do colégio não possuem trabalhos com projetos de Educação Ambiental. Os principais temas abordados pelos professores investigados são: preservação ambiental, resíduos sólidos, o aquecimento global e o efeito estufa, e a Agenda 21. Esses temas são trabalhados por meio da realização de pesquisas e de visitas, da utilização de vídeos, imagens e textos. Os professores também estimulam a produção de recursos didáticos confeccionados com materiais recicláveis. As principais dificuldades encontradas para trabalhar com a Educação Ambiental na escola foram apontadas pelos docentes, destacando-se dentre elas o desinteresse por parte dos alunos, a falta de apoio da comunidade, a carência de materiais e recursos. Frente ao apresentado, acredita-se que a escola poderia investir mais na realização de propostas de trabalho que contribuíssem com a formação de cidadãos mais críticos e participativos, que desenvolvam a capacidade de se envolver com os problemas de seu cotidiano e possam contribuir para minimizá-los ou resolvê-los. O desenvolvimento de projetos, a implementação da pedagogia de projetos ou a elaboração e implementação da Agenda 21 Escolar são alternativas que a escola possui de trabalhar o tema meio ambiente de forma interdisciplinar.
\end{abstract}

Palavras-chave: Educação ambiental. Ensino Fundamental. Professores.

Abstract: This article examines how teachers at a public school in the state of Parana deal with Environmental Education in their disciplines, as well as the importance they attach to it. The qualitative research involved eight teachers from different subject areas who work in basic education. The data were collected through questionnaires. After classifying the data it was verified that in general, high school teachers do not carry out projects about Environmental Education. But issues related to the environment are discussed by some teachers in a timely manner, ie, there are no relation to the other topics dealt in class. The main themes discussed are: environmental preservation, solid waste, global

\footnotetext{
* Prof. a de Ciências Biológicas da Faculdade Integrado de Campo Mourão - PR. E-mail: rosangelablins@yahoo. com.br

* Professor at the Biological Sciences Course at the Campo Mourão Integrated College - PR. E-mail: rosangelablins@yahoo.com.br

${ }^{* *}$ Prof. ${ }^{a}$ Mestre do Curso de Ciências Biológicas da Faculdade Integrado de Campo Mourão - PR. E-mail: lisandra. lisovski@gmail.com

${ }^{* *}$ Professor at the Biological Sciences Course at the Campo Mourão Integrated College - PR. . E-mail: lisandra. lisovski@gmail.com
} 
warming and the greenhouse effect, and Agenda 21. The main teaching resources used for dealing with these topics are: conducting research, visiting special locations, using videos, images and texts. Teachers also stimulate the production of educational resources made from recyclable materials. Teachers also pointed out the main difficulties / obstacles encountered in working with environmental education in schools; among them we can highlight students' lack of interest, lack of community support, lack of materials and resources and lack of students' awareness. In face of this, it is believed that the school could propose alternative ways to contribute to the formation of critical citizens, engaged with everyday problems that can contribute to minimize or solve them. The development of projects, research or the implementation of Agenda 21 are alternatives that the school have to deal with environment themes in an interdisciplinary way.

Keywords: Environmental education. Basic education. Teachers.

\section{Introdução}

Sabe-se que a Educação Ambiental (EA) começou a ser discutida em vários países do mundo a partir das décadas de 50 e 60. Na época, a ênfase era a educação para a conservação da natureza, pois o ambiente era visto apenas como um recurso.

Já nas décadas de 60 e 70, segundo Ribeiro (2006, p. 10), "nasce um novo ecologismo (denominado ambientalismo) em contraposição à antiga proteção da natureza”. Dessa forma, começa a nascer uma visão mais crítica da sociedade, na qual o homem passa a ser considerado como parte do ambiente.

Na década de 70, dois grandes eventos marcaram o cenário da Educação Ambiental. O primeiro foi a Conferência de Estocolmo (1972), que trouxe uma reflexão sobre o futuro do desenvolvimento da humanidade segundo a qual esta deveria repensar seu crescimento a qualquer custo, sem levar em consideração o custo ambiental. O segundo foi a Conferência de Tibilisi (1977), promovida pela UNESCO, na capital da Geórgia, ex-União Soviética.

A Declaração de Tibilisi concebe a Educação Ambiental como o meio educativo através do qual se pode compreender arti- culadamente as dimensões ambiental e social, bem como problematizar a realidade em busca das origens da crise civilizatória, em vista da formação de indivíduos e grupos sociais éticos, responsáveis e solidários para com a proteção e melhoria do meio ambiente. (RIBEIRO, 2006 p. 20)

Essa conferência foi um marco conceitual da EA, pois, segundo Leff, ela fundamentou a EA em dois princípios básicos:

1) Uma nova ética que orienta os valores e comportamentos para os objetivos de sustentabilidade ecológica e equidade social; 2) uma nova concepção de mundo como sistemas complexos, a reconstituição do conhecimento e do diálogo de saberes, convertendo a interdisciplinaridade em um princípio metodológico a ser privilegiado pela EA. (LEFF, 1999, p.113).

Dessa forma, a grande relevância da Conferência de Tibilisi foi a ruptura com as práticas reducionistas ao sistema ecológico, por estarem demasiadamente implicadas com uma educação meramente conservacionista. Ela propõe que a EA seja atrelada aos aspectos políticos, econômicos e socioculturais. 
Na década de 80, nasce o movimento da EA socialmente crítica, que associa a EA a uma análise crítica das realidades ambientais, sociais e educativas, visando à transformação das mesmas por meio de um diálogo de saberes (disciplinares e não disciplinares). Segundo Sauvé (1996), essa seria a melhor estratégia para criar um saber crítico que pudesse ser útil para a solução de problemas e para o desenvolvimento de projetos locais. É também a partir dessa década que a EA começou a ganhar dimensões públicas de grande relevância no cenário nacional, principalmente com sua inclusão na Constituição Federal Brasileira de 1988.

Na década de 90, o Brasil foi palco de uma grande conferência sobre Educação Ambiental, a Rio-92 ou Eco-92. A Conferência das Nações Unidas sobre o Meio Ambiente e Desenvolvimento tratou da crescente crise ecológica no mundo, em vista do bem-estar dos povos. Nela, estiveram reunidos representantes e chefes de estado de 179 países.

Documento fruto dessa conferência, a Agenda 21 contempla acordos e compromissos entre as nações em prol da proteção ambiental e da melhoria da qualidade de vida no mundo. Esse documento possui 40 capítulos, sendo que o capítulo 36, referente à educação, propõe o fortalecimento de atitudes, valores e ações que apoiem o desenvolvimento sustentável por meio especialmente da promoção do ensino, da conscientização e do treinamento.

Em 1992 foi criado o Ministério do Meio Ambiente e em meados do mesmo ano o IBAMA instituiu os Núcleos de Educação Ambiental em todas as suas superintendências estaduais, com o intuito de operacionalizar as ações educativas no processo de gestão ambiental na esfera estadual.

Posteriormente, em 1994, foi fundado o Programa Nacional de Educação Ambien- tal - PRONEA. Esse programa possui três componentes: (a) capacitação de gestores e educadores, (b) desenvolvimento de ações educativas, e (c) desenvolvimento de instrumentos e metodologias, contemplando sete linhas de ação:

- Educação ambiental por meio do ensino formal.

- Educação no processo de gestão ambiental.

- Campanhas de educação ambiental para usuários de recursos naturais.

- Cooperação com meios de comunicação e comunicadores sociais.

- Articulação e integração comunitária.

- Articulação intra e interinstitucional.

- Rede de centros especializados em educação ambiental em todos os estados.

Os Parâmetros Curriculares Nacionais constituem outro documento relevante publicado em 1997. Nele, o Ministério da Educação e Cultura inclui o meio ambiente como um dos temas transversais nos currículos da Educação Básica, ou seja, como um tema que deve ser trabalhado pelos professores de diferentes áreas do saber.

Segundo Krag (2007, p. 11), “em virtude da rápida degradação do planeta e consequente ameaça a qualidade de vida, tem se tornado cada vez mais emergente a abrangência da Educação Ambiental no ensino formal”, como conceito transversal a todas as disciplinas oferecidas, participando ativamente da transdisciplinaridade, “conduzindo e aplicando seus objetivos nos âmbitos sociais, políticos, culturais, religiosos, profissionais e educacionais”. (KRAG, 2007, p. 12).

Considerando a relevância da temática apresentada, esta pesquisa procurou analisar como os professores de uma escola pública 
do Município de Mamborê/PR trabalham com a Educação Ambiental em suas disciplinas, bem como a importância que atribuem à mesma. Para que essa análise pudesse ser realizada, buscaram-se respostas para as seguintes questões:

1. Como a escola organiza e implementa os Projetos de Educação Ambiental?

2. Quais são os temas relacionados à Educação Ambiental trabalhados pelos professores da escola?

3. Quais são os principais entraves/dificuldades encontrados pelos professores para trabalhar com a Educação Ambiental na escola? Como superam/ minimizam essas dificuldades?

4. Qual a importância atribuída à Educação Ambiental pelos professores da Escola?

\section{Referencial teórico}

Como se mencionou, os PCN recomendam que a Educação Ambiental seja trabalhada por todas as disciplinas que compõem o currículo escolar, ou seja, a Educação Ambiental é um tema transversal que deve ser trabalhado de forma interdisciplinar.

Segundo Zakrzevski e Coan (2003, p. 67), "a interdisciplinaridade é uma maneira de organizar e produzir conhecimentos, buscando integrar as diferentes dimensões dos fenômenos estudados”. Ela oferece um caminho dialógico, num sistema de confrontação que gera análises, sínteses e muitas vezes rupturas. Possibilita também o estabelecimento de inúmeras relações entre as disciplinas e destas com a realidade.

De acordo com os PCN (1997), a interdisciplinaridade questiona tanto a segmentação entre os diferentes campos de conheci- mentos produzidos por uma abordagem que não leva em conta a inter-relação entre eles, quanto a visão compartimentada da realidade sobre a qual a escola, tal como conhecida, historicamente se constitui. Refere-se, portanto, a uma relação interdisciplinar.

Dessa forma, a interdisciplinaridade enquanto princípio da Educação Ambiental - permite a abertura de diferentes campos de saberes, de modo a enriquecer a análise e a compreensão da realidade complexa do meio ambiente. Já a transversalidade faz referência “à possibilidade de se estabelecer, na prática educativa uma relação entre aprender conhecimentos teoricamente sistematizados (aprender sobre a realidade) e as questões da vida real e de sua transformação (aprender a realidade da realidade)” (BRASIL, 1997, p. 30).

O tema transversal meio ambiente deve ser trabalhado de forma implícita nas questões diárias de cada disciplina escolar, é preciso capacitar o aluno como cidadão que se veja como um ser histórico.

A Educação Ambiental traz para a escola um universo de significações, justamente por mexer com questões presentes na vida, no cotidiano, com as relações estabelecidas entre os seres vivos e deles com a natureza, porém só encontrará espaço a partir do momento em que o professor buscar alternativas para trabalhar os temas com ela relacionados. Uma dessas alternativas é a interdisciplinaridade.

Por meio de um trabalho interdisciplinar, professores de diferentes áreas do conhecimento ajudam o aluno a compreender um determinado problema ou situação. Por exemplo, ao trabalhar com o tema “agroquímicos”, o professor de história pode ajudar o aluno a compreender o surgimento dos agroquímicos; o professor de química pode ajudá-lo a entender a composição e os 
impactos que os agroquímicos podem causar ao homem e ao meio ambiente; o professor de biologia pode trabalhar os impactos biológicos desse produto.

A ideia do trabalho interdisciplinar nãopassa pela unificação dos conhecimentos e saberes, mas sim pela busca incessante entre eles, e é nessa construção do saber que a interdisciplinaridade se solidifica de fato, e não nos momentos posteriores, quando se busca os saberes instituídos para organizá-los.

Porém, além de reconhecerem a importância de trabalhar a Educação Ambiental de forma interdisciplinar, é preciso que os professores tenham uma compreensão mais ampla de meio ambiente. A concepção de meio ambiente do professor reflete-se, direta ou indiretamente, na sua ação pedagógica.

$\mathrm{Na}$ literatura encontram-se diferentes concepções de meio ambiente, mas serão trazidas para a discussão as representações de meio ambiente definidas por Sauvé (1996). A autora identifica sete representações de meio ambiente: ambiente como natureza, ambiente como recurso, ambiente como problema, ambiente como sistema, ambiente como meio de vida, ambiente como biosfera e ambiente como um projeto comunitário.

Segundo a referida autora, a maioria das pessoas entende meio ambiente como natureza, devendo o ser humano apreciá-la, respeitá-la e preservá-la. Para essas pessoas a concepção de natureza remete ao "ambiente original e puro [...] a natureza é como uma catedral, um monumento, que devemos admirar e respeitar” (SAUVÉ, 1996, p.19). Dessa forma, as estratégias que são utilizadas em Educação Ambiental são as que priorizam a imersão do ser humano na natureza, renovando seus laços com a mesma, desenvolvendo um sentimento de pertencimento, de admiração e de respeito pelo meio natu- ral. Na escola, tal concepção de meio ambiente reflete-se na realização de atividades que buscam levar o aluno a ter contato com a natureza, ouvir o som dos pássaros, sentir o ar puro, fazer caminhadas na mata, entre outras.

Quando as pessoas pensam no ambiente como recurso (água, ar, solo, fauna, bosque, enfim, o patrimônio natural), geralmente se percebe que os recursos ambientais encontram-se limitados e degradados. Segundo Zakrzevski e Coan (2003, p. 20), a Educação Ambiental “deve ajudar o ser humano a aprender a manejar/gerenciar o meio ambiente (recursos) para alcançar o desenvolvimento sustentável: precisamos tomar as decisões corretas para assegurar os recursos para as futuras gerações”. Dessa forma, dentre as estratégias de ensino e aprendizagem adotadas encontram-se as campanhas de economia de energia, recuperação e reciclagem.

Na concepção que relaciona o meio ambiente com problemas ambientais, destacam-se as preocupações com os impactos negativos da ação humana sobre o ambiente natural. Para Zakrzevski e Coan (2003, p. 20):

Os problemas ambientais, gerados pela crescente urbanização, industrialização acelerada, pelos modos de vida e hábitos de consumo da população ao desenvolvimento vigente, têm sido responsáveis por catástrofes ambientais, rompendo as dinâmicas ecológicas. (...) Normalmente, os problemas ambientais que afetam a vida das pessoas são os que geram maiores preocupações, e aqueles que causam efeitos a médio e longo prazo, e muitas vezes são negligenciados.

Frente ao apresentado, pode-se dizer que as estratégias educativas de Educação 
Ambiental desenvolvidas no ambiente escolar versam principalmente sobre a construção de competências para o processo coletivo de resolução de problemas ambientais, ou seja, são realizadas campanhas para limpeza de rios, nascentes, campanhas de coleta de lixo, entre outras.

Já na concepção de ambiente como meio de vida, ou seja, como o ambiente cotidiano (escola, casa, praça, local de trabalho, comunidade...) que é preciso conhecer e organizar, Zakrzevski e Coan (2003, p. 21) sinalizam que a Educação Ambiental

[...] deve buscar o estudo das relações que existem entre as pessoas, seu grupo social e os elementos naturais e transformados do meio de vida. Através de itinerários de interpretação ambiental (do bairro, do mercado, da escola, etc.) e de outras estratégias de investigação sobre o entorno (inventários do meio ambiente, experimentos, encontros, entrevistas, análise de documentos, etc.), a EA possibilita a redescoberta pelo ser humano de seu próprio meio, desenvolvendo um sentimento de pertencimento ao mesmo, que permite atuar de modo responsável, desenvolvendo o compromisso pela realidade cotidiana, deste modo melhorando as relações com o meio do qual faz parte.

Quando as pessoas pensam o ambiente como sistema, Sauvé (1996, p. 43) aponta que a compreensão de sistema "nos remete à idéia de espécie, população, comunidade biótica, ecossistema, equilíbrio ecológico, relações ecológicas, relações ambientais”. Defende-se a ideia de que a Educação Ambiental precisa auxiliar as pessoas a desenvolverem um pensamento sistêmico, auxiliando-as na construção de uma visão global, que ajude a tomar decisões.

As já citadas estratégias de ensino e aprendizagem apontadas por Zakrzevski e Coan (2003) sinalizam que devem ser favo- recidos os estudos de caso sobre problemas ambientais globais, auditorias para regular o consumo em diferentes partes do mundo. Também é importante valorizar e utilizar contos e lendas regionais.

Depois de cristalizado o conhecimento dessas representações de meio ambiente, pode-se perceber que de forma isolada elas não dão conta de trazer uma definição apropriada para meio ambiente. Mas não há dúvida de que devem ser compreendidas como sendo complementares e inter-relacionadas.

No ambiente como projeto comunitário, Sauvé (1996 apud ZAKRZEVSKI; COAN, 2003, p. 23), afirma que ele é "parte da coletividade humana, é o lugar dividido, o lugar político, o centro da análise crítica. Pelo individualismo e falta de compromisso com a própria comunidade, o ambiente clama pela solidariedade, pela democracia e pelo envolvimento individual e coletivo”.

Dessa forma, a Educação Ambiental deve buscar a participação ativa da comunidade, levando em consideração suas necessidades, sua cultura, os vínculos do contexto local com a situação global da região. Isso possivelmente possibilitará construir ou reconstruir laços de comprometimento e de responsabilidade entre as pessoas e a comunidade (escolas, grupo de idosos, lideranças religiosas, grupo de jovens, etc.) e o seu meio local.

É preciso, portanto, entender o meio ambiente em toda sua complexidade. Orellana (2001) diz que a Educação Ambiental limitada a uma ou outra das concepções apresentadas seria incompleta e responderia a uma visão reducionista da relação do meio ambiente com o mundo. Se a concepção assumida como certa de meio ambiente for reducionista, consequentemente as atividades exercidas por professores e cidadãos também o serão. 
Por essa razão não é possível deixar de concordar com Sauvè e Orellana (2001), quando elas afirmam que é através do conjunto dessas concepções inter-relacionadas e complementares que se estabelece uma relação com o ambiente. O importante não é encontrar uma definição para o termo, mas explorar as suas diferentes representações.

\section{Metodologia}

Segundo Richardson (1999), a abordagem qualitativa parte do fundamento de que há uma relação dinâmica entre o mundo real, o sujeito e o objeto; um vínculo indissociável entre o mundo objetivo e a subjetividade do sujeito.

É importante ressaltar que na pesquisa qualitativa todas as pessoas que participam devem ser reconhecidas como sujeitos que elaboram conhecimentos e produzem práticas para intervir nos problemas que identificam. Não se quer que o resultado final da pesquisa seja considerado fruto de um trabalho meramente individual, mas sim uma tarefa coletiva construída junto aos sujeitos que participarão desse trabalho. Por esses motivos, define-se a pesquisa ora apresentada como sendo qualitativa.

O universo de pesquisa foi constituído pelos professores da Escola Estadual Rui Barbosa - Ensino Fundamental, localizada no Município de Mamborê/PR, bem como pela sua equipe diretiva (diretores, vice-diretores, coordenadores pedagógicos e supervisores).

Convém ressaltar que na Escola trabalham 58 professores, dos quais oito estavam de licença (maternidade, doença, licença prêmio e dispensa para estudo). Outros dez professores trabalham no noturno e não foram envolvidos na pesquisa. Dos 40 professores que restaram, 23 são do Quadro Próprio do
Magistério Estadual (QPM) e 17 foram contratados pelo Processo Seletivo Simplificado (PSS).

Diante dessa realidade, optou-se por envolver na pesquisa apenas os professores do Quadro Próprio do Magistério (QPM), pois, além de serem efetivos, a maioria deles trabalha há muitos anos na escola. Os professores PSS não foram convidados a participar da pesquisa pelo fato de ministrarem aulas num período muito curto de tempo na escola, o que muitas vezes impede ou dificulta que elaborem e implementem projetos de Educação Ambiental no local. Assim, a amostra de pesquisa ficou constituída por 23 professores, das seguintes disciplinas: Arte, Ciências, Educação Física, Geografia, Inglês, Português, História e Matemática.

Após a definição da amostra da pesquisa, realizou-se uma reunião com a equipe diretiva e com os 23 professores selecionados, para apresentar a pesquisa e seus objetivos. Posteriormente à aceitação do convite, foram elaborados dois questionários para coleta das informações: um com oito perguntas, que deveriam ser respondidas pelos professores; e o outro com dez, que deveriam ser respondidas pelos membros da equipe diretiva.

As perguntas desses instrumentos de coleta de informações eram discursivas, ou seja, possibilitam ao entrevistado responder com mais liberdade, não ficando restrito a marcar uma ou outra alternativa. Permitiam, ainda, que o entrevistado escrevesse respostas claras sobre o tema proposto, podendo usar frases ou orações.

Segundo Richardson (1999), o questionário é o mais comum entre os instrumentos de pesquisa. Geralmente ele cumpre pelo menos duas funções: a de observar e descrever as características de um sujeito ou grupo, e a de medir determinadas variáveis individuais ou grupais. 
A aplicação dos questionários foi realizada por meio do contato direto com os sujeitos investigados. Dos 23 questionários entregues aos professores, apenas oito foram respondidos e recolhidos. É importante destacar que os professores membros da equipe diretiva não responderam ao questionário: alegaram falta de tempo para isso.

Nessa aplicação foram tomados cuidados especiais para assegurar a cientificidade da técnica, a qualidade das informações recolhidas, seu registro e a redução do volume de dados a elementos possíveis de análise. Evitou-se, portanto, influenciar os sujeitos, para não distorcer seus comportamentos ou declarações. Para Richardson (1999), o relacionamento com os entrevistados é um aspecto importante na validade da pesquisa qualitativa, mas não pode ser um procedimento prescrito.

Após o recolhimento dos questionários realizou-se uma tabulação das informações, as quais foram organizadas da seguinte forma: primeiramente ocorreu a digitação dos questionários, posteriormente elaborou-se um quadro para cada pergunta do questionário. Esse quadro foi dividido em quatro colunas: na primeira coluna atribuiu-se um código para o sujeito, na segunda digitou-se a resposta dada pelo sujeito, na terceira foram extraídas as ideias centrais contidas nas respostas dos sujeitos investigados e na quarta realizou-se a categorização das informações. O quadro apresentado a seguir ilustra o processo de organização aqui descrito.

A categorização é um procedimento que pode ser utilizado em qualquer tipo de análise em pesquisa qualitativa. Richardson (1999) afirma que as categorias podem ser estabelecidas seguindo dois caminhos: antes da coleta de dados, ou após a coleta de dados. Na pesquisa optou-se por estabelecer as categorias após a coleta e a leitura dos dados, pois dessa forma foi possível tornar as categorias mais específicas e concretas.

Richardson (1999) esclarece que as categorias concretizam as impressões que o pesquisador obteve dos dados, bem como a sua especificidade em agrupar as informações segundo a sua compreensão. Assim, diferentes pesquisadores podem construir diferentes categorias a partir do mesmo conjunto de dados, pois durante o estabelecimento das categorias estarão implícitas as experiências pessoais, os conhecimentos, as crenças e os valores do pesquisador.

Quadro 1 - Organização e tratamento das informações obtidas.

\begin{tabular}{|l|l|l|l|}
\hline $\begin{array}{l}\text { 1) Como a Escola em que você trabalha organiza e implementa projeto/atividades de Edu- } \\
\text { cação Ambiental? }\end{array}$ \\
\hline Cód & Respostas & Ideias centrais & Categorias \\
\hline Professor 1 & $\begin{array}{l}\text { Com projetos individuais referentes } \\
\text { aos termos atuais (aquecimento } \\
\text { global, efeito estufa, etc.), murais, } \\
\text { apresentações culturais. }\end{array}$ & $\begin{array}{l}\text { Realiza projetos; } \\
\text { confecciona murais; } \\
\text { realiza apresentações } \\
\text { culturais. }\end{array}$ & $\begin{array}{l}\text { Desenvolve } \\
\text { projetos de } \\
\text { Educação } \\
\text { Ambiental. }\end{array}$ \\
\hline Professor 2 & $\begin{array}{l}\text { No inicio do ano letivo, } \\
\text { especificamente na semana } \\
\text { pedagógica, é solicitado que todos } \\
\text { os professores trabalhem o tema, } \\
\text { independentemente da disciplina } \\
\text { em que atuam. Quanto aos projetos, } \\
\text { é livre a escolha e opção dos } \\
\text { profissionais da educação. }\end{array}$ & $\begin{array}{l}\text { Na semana pedagógica } \\
\text { todicitado que } \\
\text { trabalhem o tema na } \\
\text { disciplina em que } \\
\text { atuam. }\end{array}$ & $\begin{array}{l}\text { Fica a critério } \\
\text { do professor. }\end{array}$ \\
\hline
\end{tabular}




\begin{tabular}{|l|l|l|l|}
\hline Professor 3 & $\begin{array}{l}\text { Deixa livre, porém incentiva perma- } \\
\text { nentemente o Trabalho. }\end{array}$ & $\begin{array}{l}\text { Deixa a critério do } \\
\text { professor. }\end{array}$ & $\begin{array}{l}\text { Fica a critério } \\
\text { do professor. }\end{array}$ \\
\hline
\end{tabular}

\section{Análise e discussão dos dados}

Retomando o objetivo central, que é o de analisar como os professores de uma Escola Pública do Município de Mamborê/ PR trabalham com a Educação Ambiental em suas disciplinas, bem como a importância que atribuem à mesma, a partir deste momento serão realizadas a análise e discussão das informações coletadas.

A primeira questão de pesquisa buscou saber como a escola organiza e implementa os Projetos de Educação Ambiental. Com base nas respostas dos oito professores que responderam às perguntas, pode-se dizer que a escola não possui uma proposta de trabalho com projetos de Educação Ambiental. Os professores apenas são convidados a abordar o tema meio ambiente no início do ano letivo, mas fica a critério de cada professor propor atividades ou projetos. Dessa forma, os professores trabalham apenas com atividades, as quais, apesar de envolverem temas atuais relacionados ao meio ambiente, são desvinculadas de projetos específicos. Apenas um professor citou que desenvolve atividades relacionadas com o Projeto Agrinho. Seguem algumas falas que ilustram tais afirmações:

No início do ano letivo, especificamente na semana pedagógica é solicitado que todos os professores trabalhem o tema, independentemente da disciplina em que atua. Quanto aos projetos, é livre a escolha e opção dos profissionais da educação. (Professor 2)

Desenvolve atividades de Educação Ambiental por meio do Projeto Agrinho, desenvolvido pela SEED. (Professor 6)
Com projetos individuais referentes aos termos atuais (aquecimento global, efeito estufa, etc.), murais, apresentações culturais. (Professor 1)

Sabemos da importância de se desenvolver projetos de Educação Ambiental interdisciplinares, pois os mesmos constituem uma maneira de produzir conhecimentos com os alunos, trabalhar um mesmo tema em várias disciplinas, um assunto que abrange várias diferenças de fenômenos como: arborização, jardinagem, reciclagem, etc. Isso possibilita que os alunos procurem cuidar da escola, do bairro onde vivem, do local de trabalho e de sua própria casa através de estudos sobre Educação Ambiental. Faz com que cada aluno se conscientize sobre a importância da preservação do homem e da natureza.

Com relação ao Projeto Agrinho, mencionado pelo professor 6 , acredita-se que ele é um bom exemplo de que é possível trabalhar Educação Ambiental na escola. Esse projeto é o maior programa de responsabilidade social do Sistema Federação da Agricultura do Estado do Paraná - FAEP, resultado de parceria entre o Serviço Nacional de Aprendizagem Rural - SENAR, Secretarias do Estado da Educação, da Justiça e da Cidadania, do Meio Ambiente e Recursos Hídricos, da Agricultura e do Abastecimento, municípios paranaenses e diversas empresas e instituições públicas privadas.

Segundo Torres (2007, p. 7), o Programa Agrinho

[...] teve início em 1995 quando foi desenvolvida a proposta pedagógica que tinha 
por essência os "temas transversais" e o primeiro material para os alunos de $1^{\mathrm{a}} \mathrm{a}$ $4^{\mathrm{a}}$ série do Ensino Fundamental. Na ocasião priorizou-se a temática ambiental em decorrência da necessidade de responder o problema pontual de extrema gravidade no meio rural - o da contaminação de agrotóxicos.

Já no ano de 2002, o "Programa passa por mais uma ampliação para contemplar outros temas que se faziam igualmente prioritários: Meio Ambiente, saúde, cidadania e trabalho e consumo" (TORRES, 2007, p.8). Em 2006, realizou-se uma avaliação do Programa Agrinho, da qual participaram alunos, professores e a equipe diretiva de escolas, documentadores municipais, secretários municipais de educação, educadores de instituições governamentais, professores e pesquisadores de Universidades, especialistas que acompanham o Programa desde sua implantação e consultor externo da área de comunicação e educação.

Esse programa é uma iniciativa importante para a escola, pois contribui com a formação dos alunos, professores e pesquisadores, uma vez que explora a interdisciplinaridade tratando de algumas perspectivas que superam a transversalidade de conteúdos e tema.

Quando foi questionado como os professores trabalham com temas relacionados à Educação Ambiental na disciplina que lecionam, as respostas foram diversificas, conforme mostra o Gráfico 1:
Gráfico 1 - Como os professores trabalham os temas relacionados à Educação Ambiental

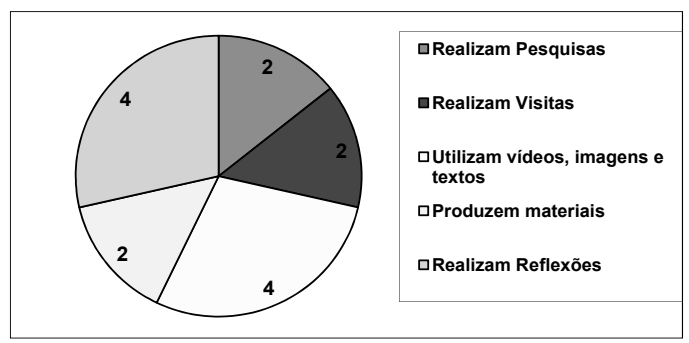

Fonte: Dados da pesquisa.

As falas apresentadas a seguir ilustram as afirmações:

Selecionando diversos tipos de textos, filmes, palestras e imagens. Refletimos, analisamos, observamos o mundo em que nos cerca; produzimos textos $e$ relacionamos as ações que cada educando pode realizar em prol do meio ambiente. Também cobramos as atitudes, como por exemplo: jogar lixo e a reciclagem. (Professor 2)

Observamos e relatamos pontos da cidade tomados pelo lixo. Fazemos a leitura visual de propagandas de incentivo ao turismo, como é a natureza (o que nos oferta, como foi um dia). Do que o homem é capaz, quais são os objetivos do homem... Debatemos estas questões. (Professor 3)

Com leituras e textos, imagens através de vídeos, conscientização através de explicações e atividades relacionadas aos fatos. (Professor 4)

Com pesquisas, vídeos relacionados aos temas. (Professor 1)

O desenvolvimento da pesquisa como uma proposta pedagógica para trabalhar na escola com temas relacionados ao meio ambiente propicia a formação de sujeitos mais críticos. A inserção da pesquisa no 
ambiente escolar constitui uma forma de superação da fragmentação dos conteúdos trabalhados dentro de cada área do saber. A pesquisa possibilita que os professores possam trabalhar os conteúdos de ensino de forma transversal e interdisciplinar.

Buscou-se ainda saber, pela pesquisa, quais são os temas relacionados à Educação Ambiental trabalhados pelos professores da escola. As respostas são apresentadas no Gráfico 2:

Gráfico 2 - Principais temas relacionados à Educação Ambiental trabalhados pelos professores

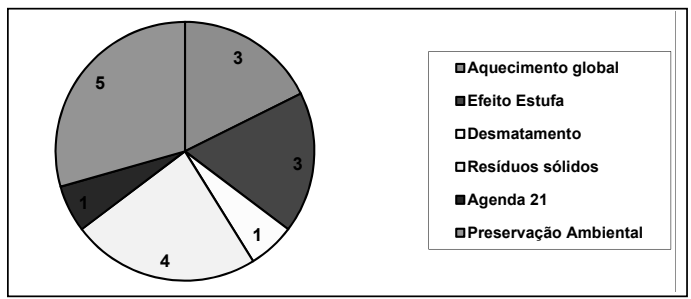

Fonte: Dados da pesquisa.

Dentre as respostas obtidas, destacamos a Agenda 21. Segundo a Comissão de Meio Ambiente e Qualidade de Vida na Escola - COM-VIDA, a Agenda 21 é um instrumento para a escola "planejar suas atividades, fazer projetos coletivos que possam realmente transformar a realidade, aumentar seu diálogo com a comunidade de seu município, e se ligar em uma proposta de Agenda global” (BRASIL, 2007, p.22).

Além da realização de pesquisas mencionadas anteriormente, a Agenda 21 é outra proposta de trabalho que possibilita a interdisciplinaridade. Através da Agenda 21 os alunos podem ter uma maior compreensão da realidade em que vivem. Ela estimula, além do envolvimento dos alunos, a participação de professores, da família e da comunidade para compreender e até mesmo minimizar problemas locais.

Os professores também foram questionados sobre quais são as principais dificuldades/entraves encontrados pelos professores para trabalhar com a Educação Ambiental na escola. As respostas estão apresentadas no Gráfico 3.

Gráfico 3 - Principais dificuldades/entraves encontrados pelos professores para trabalhar com a Educação Ambiental

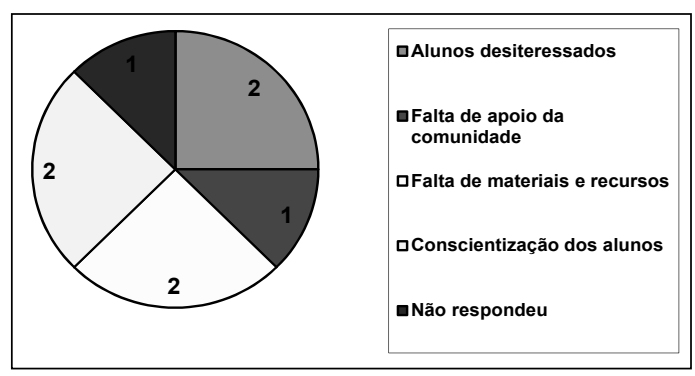

Fonte: Dados da pesquisa.

Os professores investigados enfrentam essas dificuldades/entraves com organização das aulas e atividades, e com muita força de vontade, conforme os depoimentos a seguir:

A minha luta é constante dentro e fora da escola. Cada cidadão deve fazer a sua parte, mesmo que tenham obstáculos. "Quem sabe faz a hora não esperar acontecer”. (Professor 2)

Não desistir nunca. Por mais problemático que seja, não podemos desanimar, pois faz parte do processo histórico do desenvolvimento do ser humano. Tudo 
é modificado conforme a necessidade e a oportunidade de conhecer e vencer os obstáculos do cotidiano, bem como a Evolução do Homem. (Professor 7)

Os professores sinalizaram algumas condições que deveriam ser oferecidas pela escola para trabalhar com a Educação Ambiental. São elas: capacitação profissional e disponibilidade de recursos didáticos.

Palestras para os professores, material didático, filmes, proporcionar uma oficina de como elaborar projetos. O que falta mesmo é a informação. as condições de trabalho são importantes, mas o conhecimento é imprescindível. Muitos profissionais precisam atualizar a forma de encaminhar os conteúdos. (Professor 2)

A formação continuada é fundamental para os professores. Ela pode ocorrer de diferentes formas, como, por exemplo, através da participação dos professores em encontros, simpósios, seminários, na formação de grupos de estudo, na realização de cursos de Pós-Graduação, na participação em cursos de aperfeiçoamento, por meio das reuniões pedagógicas realizadas na escola, estudos individuais, realização de pesquisa, entre outros.

Dessa forma, a formação continuada, acima de tudo, é um momento de reflexão sobre a própria prática pedagógica. Assim, o professor que está sempre em busca de uma formação tende a ampliar o seu campo de trabalho e atuação.

\section{Considerações finais}

Esta pesquisa oportunizou o conhecimento de como os professores de uma Escola Pública do Município de Mamborê/PR trabalham com a Educação Ambiental em suas disciplinas, bem como a importância que atribuem à mesma.

Os resultados sinalizaram de uma forma geral que a Escola Estadual Rui Barbosa não possui uma proposta de trabalho com projetos de Educação Ambiental. Por mais que a equipe diretiva da escola estimule os professores a trabalharem de forma interdisciplinar o tema meio ambiente, o mesmo é desenvolvido apenas por algumas disciplinas, de forma pontual.

Os principias temas abordados pelos professores investigados são: preservação ambiental, resíduos sólidos, o aquecimento global e o efeito estufa, e a Agenda 21. Já os principais recursos didáticos utilizados para trabalhar os referidos temas são: realização de pesquisas; realização de visitas; e utilização de vídeos, imagens e textos. Os professores também estimulam a produção de recursos didáticos confeccionados com materiais recicláveis.

Os docentes envolvidos na pesquisa apontaram, também, os principais entraves/ dificuldades encontrados para trabalhar com a Educação Ambiental na escola. Entre eles é possível destacar o desinteresse por parte dos alunos, a falta de apoio da comunidade, a falta de materiais e recursos, a pouca conscientização dos alunos. Os professores sinalizaram que essas dificuldades poderiam ser minimizadas por meio der maior disponibilidade de recursos didáticos por parte da escola e pela realização da formação continuada.

Além disso, acredita-se que a escola poderia investir mais na realização de propostas de trabalho que contribuam com a formação de cidadãos mais críticos e participativos, que desenvolvam a capacidade de se envolver com os problemas de seu cotidiano e, por meio de uma ação responsável, possam contribuir para minimizá-los ou resolvê-los. 
O desenvolvimento de projetos, a implementação da pedagogia de projetos ou a elaboração e implementação da Agenda 21 Escolar são alternativas que a escola possui de trabalhar o tema transversal meio ambiente de forma interdisciplinar, envolvendo não apenas os alunos, mas toda a comunidade escolar, possibilitando que as pessoas o compreendam de uma forma mais ampla e complexa. É uma oportunidade de o conhecimento transpor os muros da escola.

A escola investigada possui uma estrutura boa, com amplo espaço. O pátio é bastante arborizado. Assim, sugere-se que esse espaço seja bem utilizado pelos professores. Ele poderia tornar-se um recurso didático importante, que facilitaria a construção de conhecimentos por parte dos alunos. Projetos relacionados à preservação e conservação desse espaço poderiam ser desenvolvidos em diferentes disciplinas. Outra sugestão seria a realização de projetos que tivessem como resultados a construção de jardim, pomar, horta, horto com plantas medicinais, entre outras.

E, para finalizar, reforça-se a importância de os professores formarem grupos de estudos na escola, pois a formação continuada é fundamental para o desenvolvimento profissional docente e, consequentemente, para a melhoria da prática pedagógica. Seria muito importante, ainda, que os professores aproveitassem a hora atividade para planejarem atividades interdisciplinares, contribuindo assim para um ensino mais articulado com as necessidades formativas dos próprios alunos e com o desenvolvimento da comunidade escolar da qual fazem parte.

\section{Referências}

BRASIL. Secretaria de Educação Fundamental. Parâmetros curriculares nacio- nais: apresentação dos temas transversais, ética. Brasília: MEC/SEF, 1997.

. Ministério da Educação. Secretaria de Educação Continuada, Alfabetização e Diversidade. Comissão de meio ambiente e qualidade de vida na escola: construindo Agenda 21 na escola. 2. ed. Brasília: MEC, Coordenação Geral de Educação Ambiental, 2007.

KRAG, M. N. A união entre a educação ambiental e o projeto político-pedagógico: um enfoque sobre a transversalidade da questão. Trabalho de conclusão de curso. Belém: Centro Universitário do Pará. Curso de Licenciatura em Biologia, 2007.

LEFF, E. Educação Ambiental e desenvolvimento sustentável. In: REIGOTA, M. (Org.). Verde cotidiano: o meio ambiente em discussão. Rio de Janeiro: DP\&A, 1999.

ORELLANA, I. La comunidad de aprendizaje en educación ambiental. Una estrategia pedagógica que are nuevas perpectivas en el marco de los cambios educacionales atuales. Tópicos em Educación Ambiental, México, v. 3, n.7, p.43-51, ago. 2001.

PROGRAMA NACIONAL DE EDUCAÇÃO AMBIENTAL - PRONEA / Ministério do Meio Ambiente, Diretoria de Educação Ambiental; Ministério da Educação. Coordenação Geral de Educação Ambiental. 3. ed. Brasília: Ministério do Meio Ambiente, 2005.

RIBEIRO, M. W. Os conteúdos ambientais em livros didáticos de Geografia de $1^{\circ}$. e $2^{\circ}$. ciclos do ensino fundamental. Dissertação (Mestrado em Educação) - UFPR, Curitiba, 2006.

RICHARDSON, R. J. Pesquisa social, métodos e técnicas. 3. ed. Exemplar 4: São Paulo: Atlas, 1999.

SAUVÉ, L. Envirnmental Education
and Sustainable Development: A


Further Appraisal. Canadial Journal of Environmental Education, v.1, p.7-54, 1996.

SAUVÉ, L.; ORELLANA, I. A formação continuada de professores em educação ambiental: a proposta EDAMAZ. In: SANTOS, J. E.; SATO, M. A contribuição da educação ambiental à esperança de Pandora. São Carlos: RIMA, 2001.

TORRES, P. L. (Org.). Alguns fios para entretecer o pensar e o agir. Curitiba: SENAR-PR, 2007.

ZAKRZEVSKI, S. B.; COAN, C. M. O diálogo dos saberes. In: ZAKRZEVSKI, Sônia Balvedi (Org.). A educação ambiental na escola: abordagens conceituais. Erechim: Edifapes, 2003.

ZAKRZEVSKI, S. B.; COAN, C. M. Representações paradigmáticas sobre o ambiente. In: ZAKRZEVSKI, Sonia Balvedi. Educação ambiental na escola. Erechim: Edifapes, 2003.

Enviado em: 01/11/2009

Aceito em: 03/03/2011 